\title{
Erratum to: Global DNA methylation patterns in Barrett's esophagus, dysplastic Barrett's, and esophageal adenocarcinoma are associated with BMl, gender, and tobacco use
}

\author{
Andrew M. Kaz ${ }^{1,2,3^{*}}$, Chao-Jen Wong ${ }^{2}$, Vinay Varadan ${ }^{4}$, Joseph E. Willis ${ }^{5}$, Amitabh Chak ${ }^{4,6}$ and William M. Grady ${ }^{2,3}$
}

\section{Erratum}

Following publication of this article [1], it has come to our attention that the following publication should have acknowledged the DeGregorio Family Foundation and the Price Family Foundation as providing funding for the studies and for supporting the work.

\begin{abstract}
Author details
'Gastroenterology Section, VA Puget Sound Health Care System, Seattle, WA 98108, USA. ${ }^{2}$ Clinical Research Division, Fred Hutchinson Cancer Research Center, Seattle, WA 98109, USA. ${ }^{3}$ Department of Medicine, University of Washington School of Medicine, Seattle, WA 98195, USA. ${ }^{4}$ Case

Comprehensive Cancer Center, Case Western Reserve University, Cleveland, $\mathrm{OH}$ 44106, USA. ${ }^{5}$ Department of Pathology, Case Western Reserve University School of Medicine, Cleveland, OH 44106, USA. 'Division of Gastroenterology, Case Western Reserve University School of Medicine, Cleveland, OH 44106, USA.
\end{abstract}

Received: 17 February 2017 Accepted: 27 February 2017

Published online: 01 March 2017

\section{Reference}

1. Kaz AM, Wong CJ, Varadan V, Willis JE, Chak A, Grady WM. Global DNA

methylation patterns in Barrett's esophagus, dysplastic Barrett's, and

esophageal adenocarcinoma are associated with BMl, gender, and tobacco

use. Clin Epigenetics. 2016;8:111. doi:10.1186/s13148-016-0273-7.

\footnotetext{
*Correspondence: Andrew.Kaz@va.gov; akaz@fhcrc.org

${ }^{1}$ Gastroenterology Section, VA Puget Sound Health Care System, Seattle, WA 98108, USA

${ }^{2}$ Clinical Research Division, Fred Hutchinson Cancer Research Center, Seattle, WA 98109, USA
} 